\title{
Characteristic atmosphere and ocean interaction in the coastal and marine environment inferred from infrasound at Terra Nova Bay, Antarctica - observation and initial data -
}

\author{
Masaki Kanao ${ }^{1,}$, Yongcheol Park ${ }^{2}$, Takahiko Murayama ${ }^{3}$, Won Sang Lee ${ }^{2}$, \\ Masa-yuki Yamamoto ${ }^{4}$, Hyun Jae Yoo $^{2}$, Yoshiaki Ishihara ${ }^{5}$, Jinseok Kim², Takuma Oi ${ }^{6}$, \\ Jin Hoon Jung ${ }^{2}$
}

\author{
${ }^{1}$ National Institute of Polar Research, Research Organization of Information and Systems, Tokyo, Japan \\ ${ }^{2}$ Korea Polar Research Institute, Incheon, Republic of Korea \\ ${ }^{3}$ Japan Weather Association, Tokyo, Japan \\ ${ }^{4}$ Kochi University of Technology, Japan \\ ${ }^{5}$ Japan Aerospace Exploration Agency, Sagamihara, Japan \\ ${ }^{6}$ Toho Mercantile Co., Ltd, Tokyo, Japan
}

\author{
Article history \\ Received January 24, 2017; accepted June 13, 2017. \\ Subject classification: \\ Infrasound, Antarctica, Terra Nova Bay, Microbaroms, Polar environment.
}

\section{ABSTRACT}

Characteristic features of infrasound waves observed in the Antarctic reveal physical interaction involving surface environments around the continent and Southern Ocean. In December 2015, an infrasound array (100 $\mathrm{m}$ spacing) by three sensors (Chaparral Physics Model 25, with a detectable frequency range of 0.1-200 Hz), together with a broadband barometer (Digiquartz Nano-Resolution Model 6000-16B Barometer, with a detectable frequency range of 0-22 Hz) were installed at Jang Bogo Staion, Terra Nova Bay, Antarctica by the Korea Arctic and Antarctic Research Program (KAARP). The initial data recorded by the broadband barometer contain characteristic signals originated by surrounding environment, including local noises such as katabatic winds. Clear oceanic signals (microbaroms) are continuously recorded as the background noises with predominant frequency around $0.2 \mathrm{~s}$ at the austral summer on December. Variations in their frequency context and amplitude strength in Power Spectral Density had been affected by an evolution of sea-ice surrounding the Terra Nova Bay. Microbaroms measurement is a useful tool for characterizing ocean wave climate, complementing other oceanographic, cryospheric and geophysical data in the Antarctic. Continuous infrasound observations in Terra Nova Bay attain a new proxy for monitoring environmental changes such as the global warming, involving cryosphere dynamics, as well as the volcanic eruptions in Northern Victoria Land, Antarctica.

\section{Introduction}

Infrasound is a pressure wave with a frequency range from cut-off frequency of sound $(3.21 \mathrm{mHz}$, for a $15^{\circ} \mathrm{C}$ isothermal atmosphere) to the lowest limit of human audible band $(20 \mathrm{~Hz})$ [Hedlin et al. 2002]. This frequency band is a new horizon for conducting remote sensing of the physical environment of Earth's atmosphere. Infrasound waves have been generated by a lot of kinds of environmental sources, including volcanic eruptions, ocean waves, earthquakes, thunders, sprites, fireballs, meteorite falls, artificial re-entry of vehicles, and auroral activities in polar region [Wilson and Olson, 2005; Matoza et al. 2007; Garces et al. 2007, 2008; Arrowsmith et al. 2005; Le Pichon et al. 2005; Wilson, 1996, 2005; Figure 1]. At the Sumatra-Andaman earthquake of 26 December 2004, in addition to the great 'tsunami waves' induced infrasound waves were observed as disturbances in upper atmosphere [Iyemori et al. 2005]. Another remarkable example is the 2011 Tohoku-Oki, Japan earthquake $(\mathrm{Mw}=9.0)$ which also produced unequivocal infrasound signals associated with the large tsunami [Arai et al. 2011].

The effects on generating infrasound by oceanic swells can be modulated by the presence of sea-ice in 


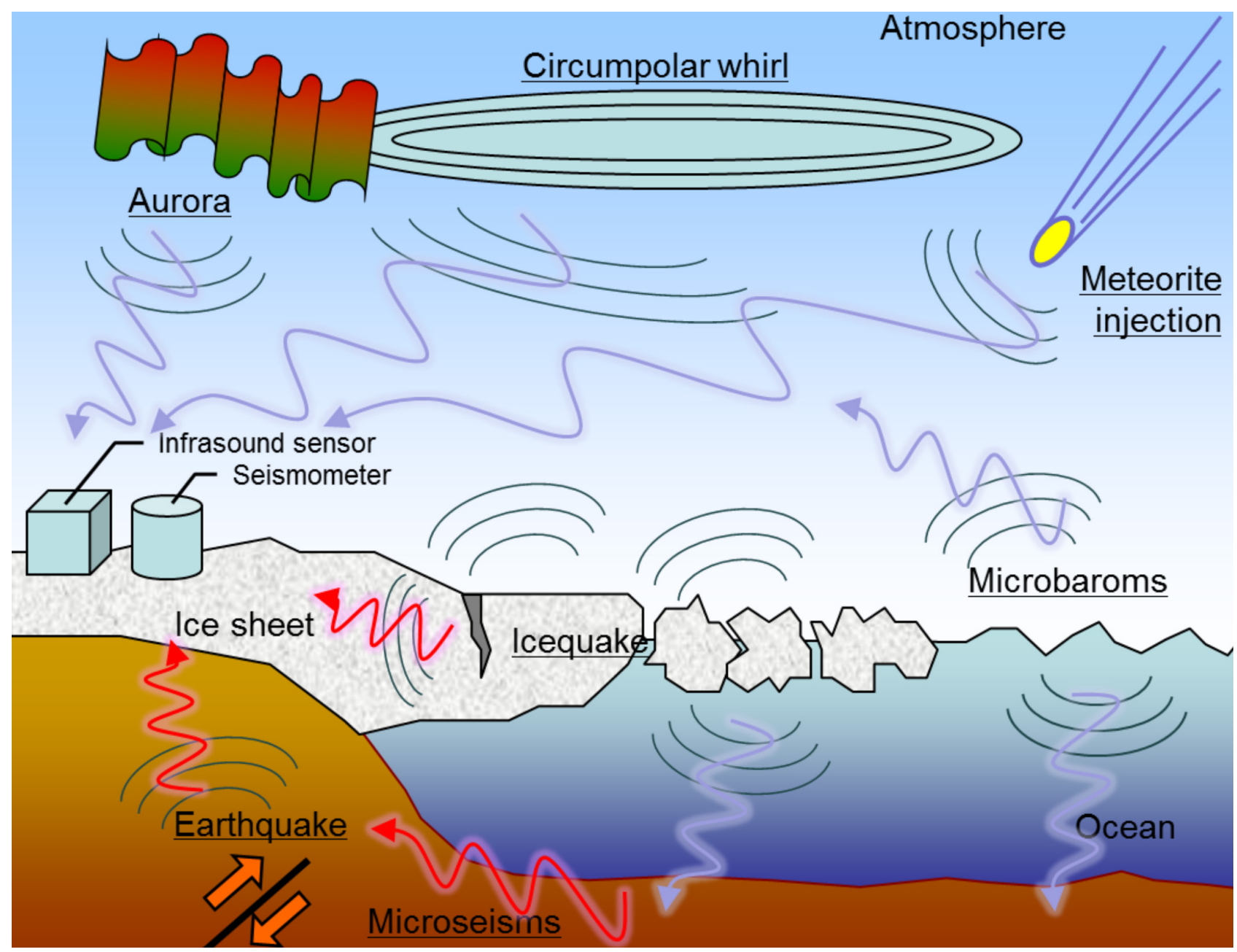

Figure 1. Schematic illustration of infrasound wave propagation and their candidate of generating sources in the Antarctic margins and Southern Ocean. Interaction among atmosphere--ocean--cryosphere--solid earth system are involved to generate the seismic, infrasonic and hydro-acoustic waves in polar region.

polar region and are influenced by how they are related to the atmosphere - ocean - cryosphere system [Kanao et al. 2012]. On the infrasound data recorded at the Lützow-Holm Bay (LHB), Eastern Dronning Maud Land, East Antarctica are also seasonally affected by sea-ice contexts and spreading area [Ishihara et al. 2015, Murayama et al. 2015]. Since the measurement of infrasound in the Antarctic is a useful proxy for characterizing ocean wave climate and global storm intensity, revealing the physical interaction mechanisms between the multiple spheres would possibly prove an indicator of environmental change such as global warming, involved cryosphere evolution, seismicity, volcanic eruption in southern high latitude.

Korean secondary Antarctic station, the Jang Bogo Station $\left(74^{\circ} 37.4^{\prime} \mathrm{S}, 164^{\circ} 13.7^{\prime} \mathrm{E}\right)$ was officially started since February 2014. The Station is located in Terra Nova Bay, Northern Victoria Land on the eastern flank of the Ross Sea rift, part of the West Antarctic rift system, one of several large tectonic prov- inces of the Earth formed by Cretaceous to Cenozoic extension (Figure 2). The rift shoulder consists of the Transantarctic Mountains, which form the morphological and geological boundary between East and West Antarctica [Behrendt and Cooper 1991, Rocchi et al. 2002]. Seismic network observation around the Terra Nova Bay have been conducted since 2010 by the Korea Arctic and Antarctic Research Program (KAARP) to reveal the deep crustal and upper mantle structure and monitor the seismicity, volcanic eruption activity by Mt. Melbourne [Park et al. 2014].

In this paper, characteristic features of infrasound waves recorded at Jang Bogo Staiton, Terra Nova Bay is demonstrated by showing the initial data retrieved during the pilot observation in austral summer on December 2015. Background signals with a peak of a few seconds in its intrinsic period are investigated, associated with far-field loading effects from Southern Ocean. Time variations in infrasound wave amplitudes and frequency content are particularly studied in the power spectral densities 


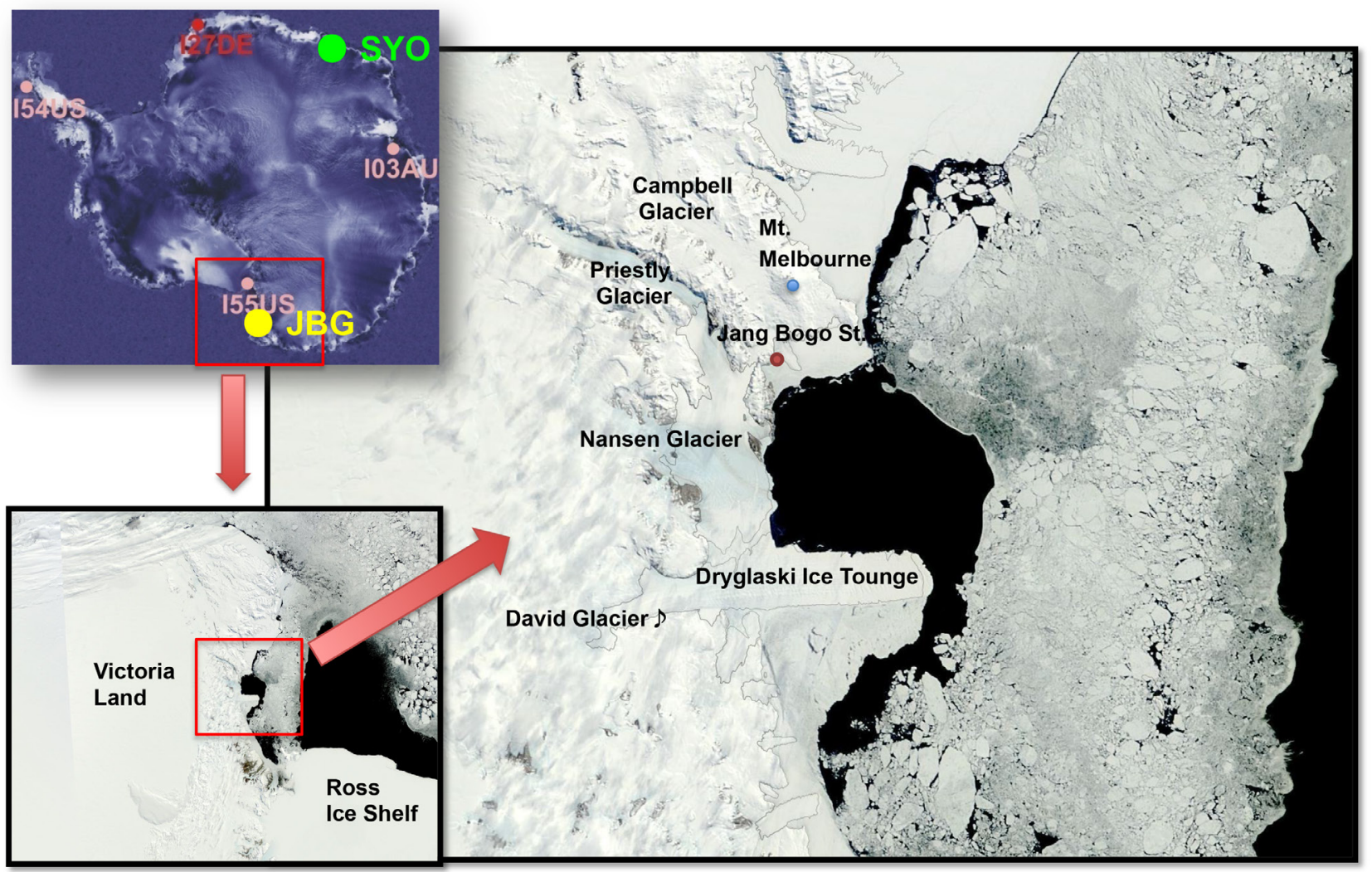

Figure 2. (upper left) Location map of Jang Bogo Station (JBG), Syowa Station (SYO), currently operating CTBTO stations (IS27 DE, IS55 US), together with planned CTBTO stations (IS03 AU, IS54 US) in Antarctica. (lower left and right) Expanded area map of Terra Nova Bay and surrounding region in Victoria Land and Ross Sea, Antarctica. Background image is the MODerate resolution Imaging Spectroradiometer (MODIS) satellite on December 02, 2015 (by NASA; https: / / worldview.earthdata.nasa.gov).

(PSD) of recorded signals.

\section{Observations at Jang Bogo Station}

During the austral summer in 2015-2016, an international project on the basis of multi-desciplinary geophysical investigation had been conducted around the Terra Nova Bay for the purpose to reveal the physical interaction among the atmosphere - ocean - cryosphere - solid earth system, as one of the major projects of KAARP. The geophysical project had been carried out by an international team named as "Extreme Geophysics Group (EGG)", composed of 20 scientists/engineers majority from Korea, and others from USA, New Zealand, Australia and Japan. The EGG activities in 2015-2016 austral summer season contained field operations in both onshore and offshore by using several technical approaches of seismology, geodesy, glaciology and marine geophysics. The offshore operation were conducted by utilizing several specific equipment on the ice-breaker vessel "Araon". They contained multi-narrow beams to image the seafloor topography, hydro-acoustic and Conductivity-Temperature-Depth (CTD) observations, in addition to related marine surveys around the Terra Nova Bay, Ross Sea and Amundsen Bay area, West Ant- arctica. In particular, side-scan imaging by using multi-narrow beams operation tried to figure out the cross section of the Dryglaski Ice Tongue, which is the most outlet part of the David Glacier.

On the contrary, onshore operation included establishment/maintenance of field geophysics stations around Terra Nova Bay, Mt. Melbourne, major icestreams of the Priestly, Nansen and David Glaciers by utilizing hericopters, which departed from Jang Bogo Station (Figure 2). The field stations outside the main base were composed of 11 seismic stations, 15 GPS stations, 2 glacier tilt-meter stations and 5 meteorological stations (the AMIGOS system; http://thistle. org/k-amigos3/). These observations had been trying to detect the time-space variations causing by dynamic cryosphere, associated with interaction between ocean, shallow atmosphere and near-surface of the solid earth around the Northern Victoria Land. At the upper stream of David Glaciers, the deployed stations intended to find the precise distribution and dynamics of sub-glacial lakes. In addition to these field stations, inside the Jang Bogo Station, long-term geophysical observations have been carring out at moment by seismometers, GPS, gravity meter and infrasound sensors. 


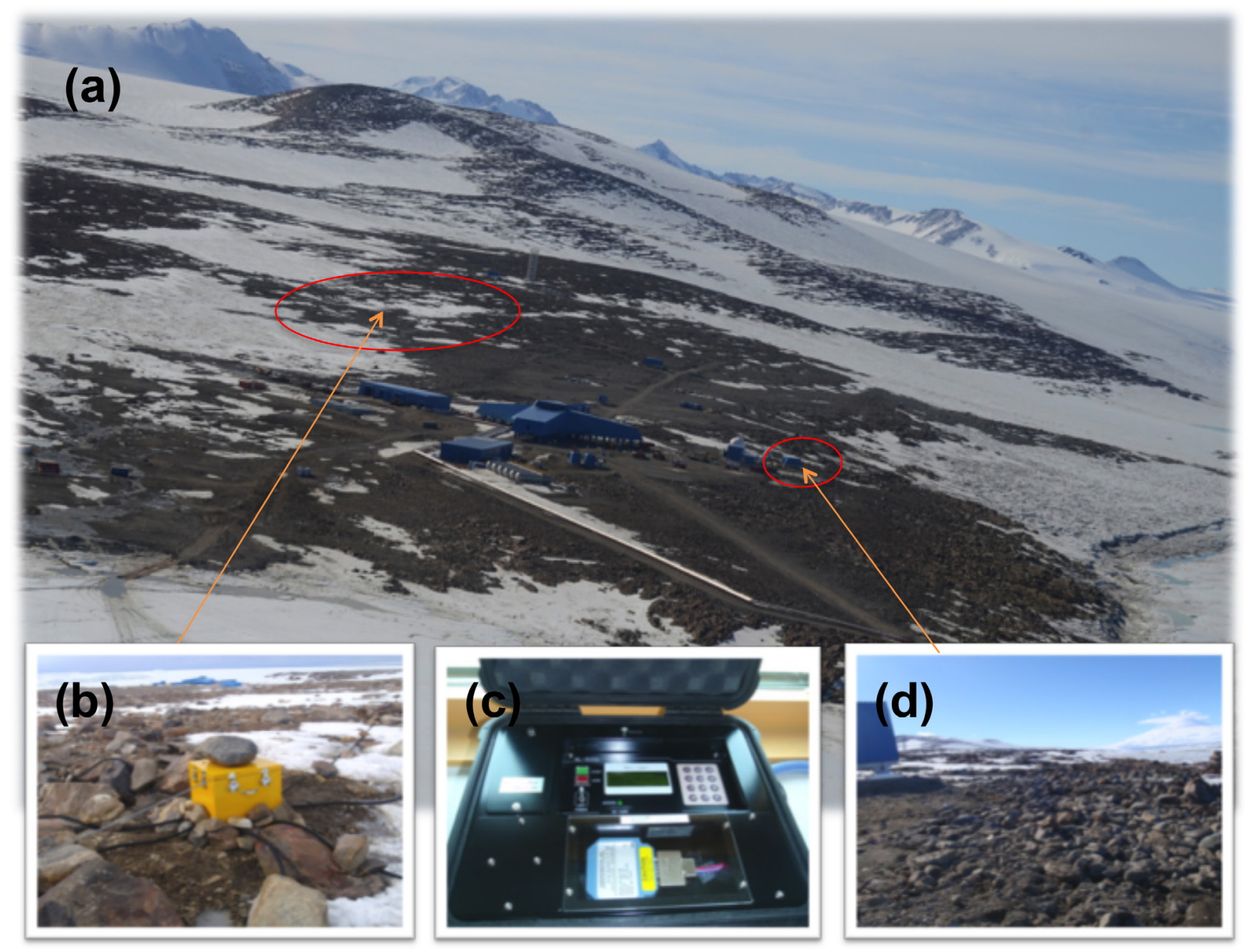

Figure 3. (a) Photo of Jang Bogo Station on December 2015. North direction is the top of this photo. Locations of infrasound array (red open circle) by Chaparral Physics Model 25 sesnors (b), Digiquartz Nano-Resolution Model 6000-16B Barometer used in this study (c), geophysical observation hut (d; red open circle) are also inserted.

In austral summer in 2015-2016, originally deploying seismic station until then was moved from near geophysical observation hut toward a new location where $500 \mathrm{~m}$ northwest direction from main buildings. It is also noticed that data aquisition of the Superconducting Gravimeter (SG) was started from January 2016 inside the small vault where very close to the geophysical observation hut (Figure 3d).

Along with these other geophycsial operations in Jang Bogo Station, an infrasound array (100 m spacing) was newly established by combining three same-specification or spec sensors (Chaparral Physics Model 25 , with a detectable frequency range of $0.1-200 \mathrm{~Hz}$ ) inside the Station, where $500 \mathrm{~m}$ northwest direction from main buildings and geophysical observation hut (Figure 3a). The Chaparral Physics sensors for the array were installed at exposed rocks/sediments and set inside the adiabatic wooden box, attached by eight airpipes (hose arrays; Figure $3 \mathrm{~b}$ ). The hose array alignment aimed to reduce the wind noises by adopting the mechanical low-pass filtering. The similar hose array has been conducted near the Syowa Station, East Antarctica (see the Figure 6 of [Murayama et al. 2015]). In addition to the Chaparral Physics sensor array, a broadband barometer (Digiquartz Nano-Resolution Model 6000-16B Barometer (Figure 3c), with a detectable frequency range of $0-22 \mathrm{~Hz}$ ) was installed inside the geophysical observatory hut, so as to combine with the data by the Chaparral sensor array. A triangle shape air-pipes were attached to the Barometer for the same purpose of to reduce wind noises (Figure 3). The data have been logging in the acquisition system for each sensors, partial data have been sending to KOPRI by using LAN and Intersat telecommunication system equipted at Jang Bogo Station.

These infrasound deployments were conducted on December 2015 by corraboration between members of the Korea Polar Research Institute (KOPRI) and the National Institute of Polar Research (NIPR) of Japan, as one of the activities of EGG project. The infrasound observations will be continued over few years to detect a long-term variability of infrasound 
signals. During winter season, sincere supports for instrumentation maintenance have been given by overwintering expedition members.

\section{Initial Data}

In this Chapter, characteristics of initial data in mid-December 2015 retrieved from Nano-Resolution Model 6000-16B Barometer is demonstrated; the sensor has been deploying inside the geophysical observation hut of Jang Bogo Station. Figure 4a- 4c represent the PSDs and their original time-domain infrasound signals of 24 hours on 13 December, 2015 for different frequency bands of $0-50 \mathrm{~Hz}(4 \mathrm{a}), 0-10 \mathrm{~Hz}$ (4b) and $0-2 \mathrm{~Hz}(4 \mathrm{c})$, respectively. Wind speed data of the Station is also plotted on Figure 4c. Several short-term (a few minutes - a few tens of minutes) spike-type noises are recognized for the day; the signals are considered to be wind noises presumably correspond to the time-window for strong "katabatic winds". Because of the Jang Bogo Station locates very close to the southern coast facing to Terra Nova Bay, the northward oriented "katabatic winds" can be predominant candidate of generating the spike-type infrasound noises. Moreover, continuous signals with approximately $0.2 \mathrm{~Hz}$ are clearly identified in the PSD of Figure 4c, which correspond to the "microbaroms" from the ocean, where is offshore of Terra Nova Bay.

Figure $5 \mathrm{a}$ and $5 \mathrm{~b}$ are the PSDs and their original time-domain infrasound signals for four days on 12-15 December, 2015 by Nano-Resolution Model 6000-16B Barometer for frequency band of $1-10 \mathrm{~Hz}$ (5a) and $0.01-2 \mathrm{~Hz}(5 \mathrm{~b})$. In the figures, as seen in Figure 4 , predominant continuous signals with approximately $0.2 \mathrm{~Hz}$ can be identified, which correspond to the microbaroms from Southern Ocean. Local wind noises (caused mainly by "katabatic winds") are also recognized in several time windows during the four days. In particular, the latter half on 12 December was the strongest and the longest duration of the windy time zone. Time variations in frequency context are not clear within these days, therefore, it is required to monitor long-period over a few months or a few years in order to detect the long-term variability including seasonal dependence.

Intrinsic periods for the "microbaroms" appearing in infrasound data correspond to the co-oscillation with oceanic loading effects on solid-earth ("microseisms") from Southern Ocean, just as is seen in seismographs at Antarctic stations [Grob et al. 2011, Kanao et al. 2012]. The prominent microbaroms peak approximately $0.2 \mathrm{~Hz}$ are caused by nonlinear interac-

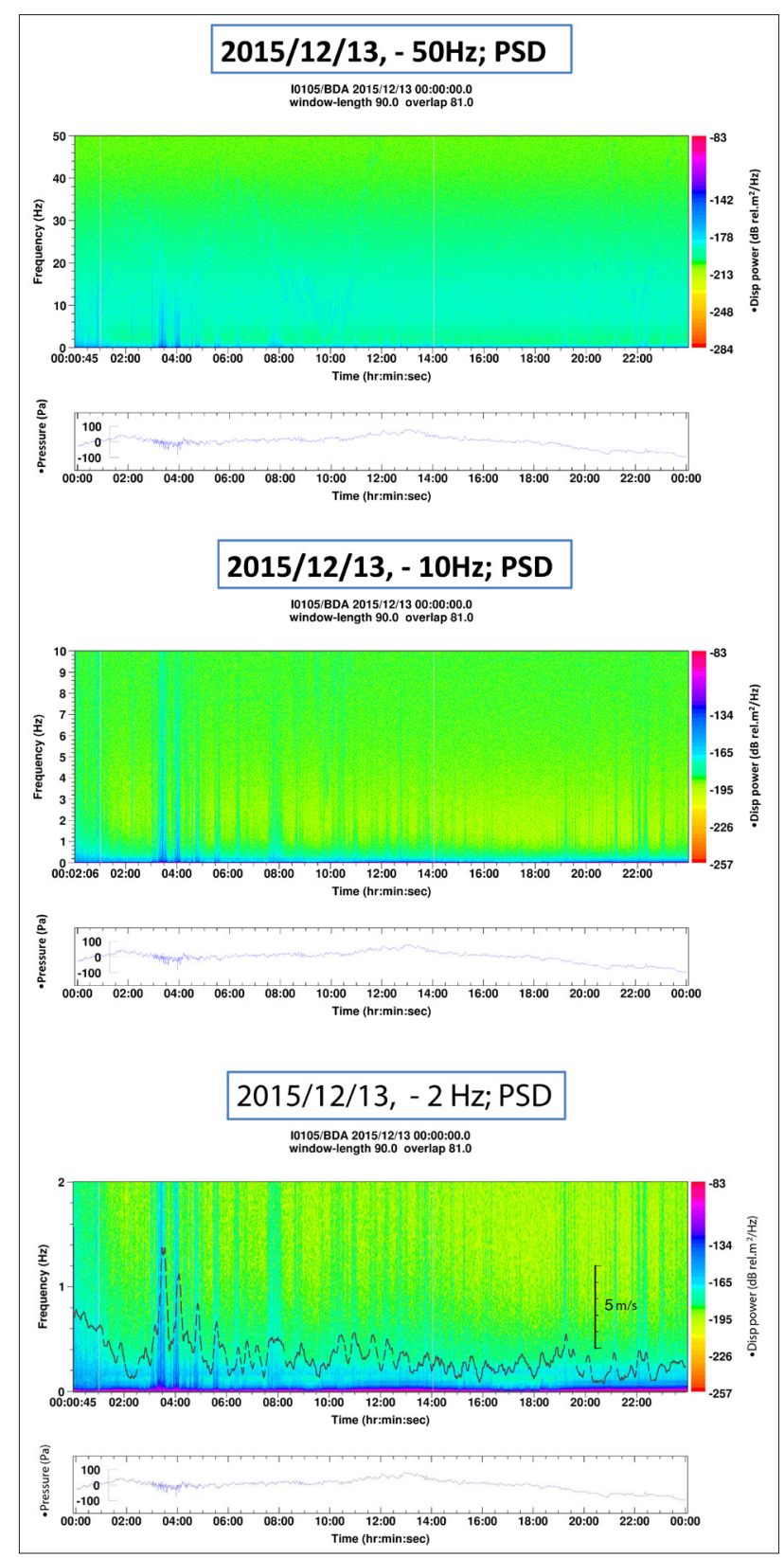

Figure 4. (a) (upper) Power spectral densities (PSD) of infrasound signals for frequency band of $0-50 \mathrm{~Hz}$ (Nano-Resolution Model 6000-16B Barometer at Jang Bogo, geophysical observation hut) for 24 hours data on 13 December, 2015. The vertical axis of right hand side indicates "Displacement Power" with the unit by ( $\mathrm{dB}$ relative to $\mathrm{m}^{2} / \mathrm{Hz}$ ). (lower) Original time-domain infrasound signals corresponding to the upper figure of PSD. (b) (upper) PSD of infrasound signals for frequency band of $0-10 \mathrm{~Hz}$ (Nano-Resolution Model 6000-16B Barometer at Jang Bogo, geophysical observation hut) for 24 hours data on 13 December, 2015. (lower) Original time-domain infrasound signals corresponding to the upper figure of PSD. (c) (upper) PSD of infrasound signals for frequency band of 0-2 Hz (Nano-Resolution Model 6000-16B Barometer at Jang Bogo, geophysical observation hut) for 24 hours data on 13 December, 2015. Wind speed data of the Station is also plotted by broken line. (lower) Original time-domain infrasound signals corresponding to the upper figure of PSD. Predominant continuous signals with approximately $0.2 \mathrm{~Hz}$ can be seen, which correspond to the microbaroms from the Ocean.

tion of interfering ocean wave components that produce a pressure perturbation at the same frequency 


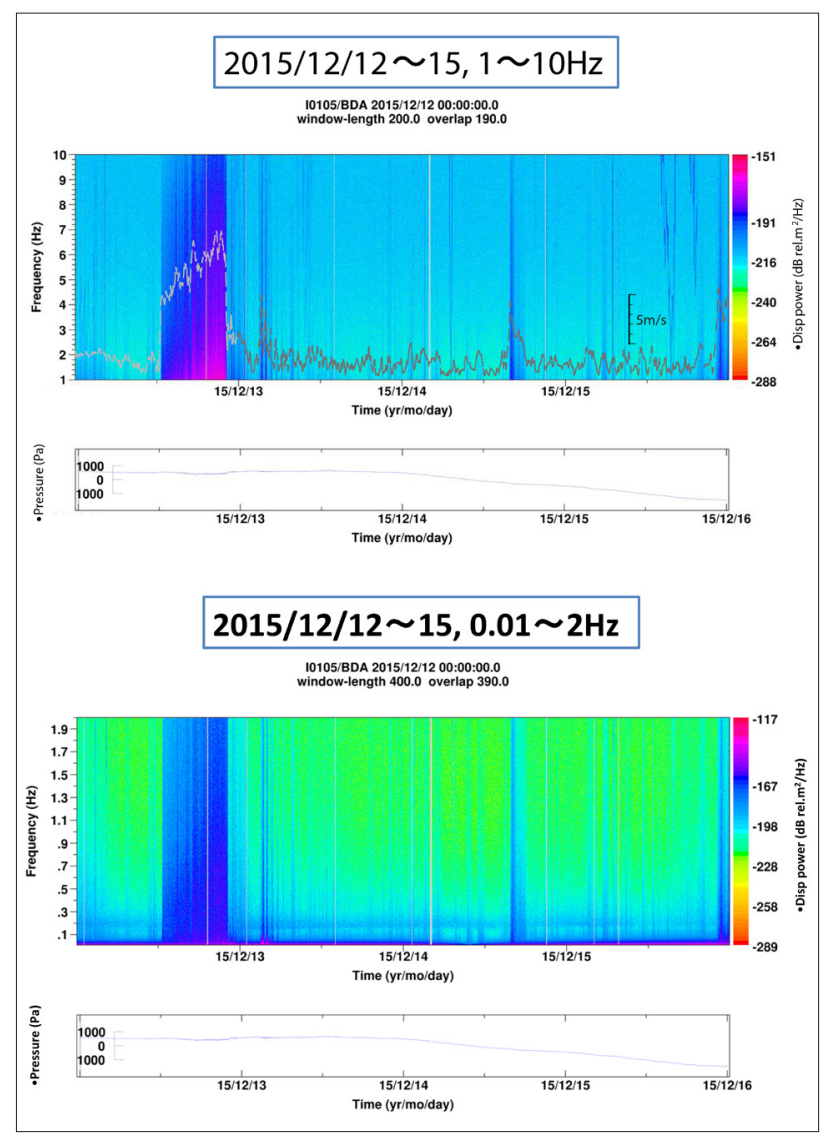

Figure 5. (a) (upper) PSD of infrasound signals for frequency band of $1-10 \mathrm{~Hz}$ (Nano-Resolution Model 6000-16B Barometer at Jang Bogo, geophysical observation hut) for 4 days data on 12-15 December, 2015. The vertical axis of right hand side indicates "Displacement Power" with the unit by ( $\mathrm{dB}$ relative to $\mathrm{m} 2 / \mathrm{Hz})$. Wind speed data of the Station is also plotted by broken line. (lower) Original time-domain infrasound signals corresponding to the upper figure of PSD. (b) (upper) PSD of infrasound signals for frequency band of $0.01-2 \mathrm{~Hz}$ (Nano-Resolution Model 6000-16B Barometer at Jang Bogo, geophysical observation hut) for 4 days data on 1215 December, 2015. The vertical axis of right hand side indicates "Displacement Power" with the unit by (dB relative to $\mathrm{m} 2 / \mathrm{Hz}$ ). (lower) Original time-domain infrasound signals corresponding to the upper figure of PSD. Predominant continuous signals with approximately $0.2 \mathrm{~Hz}$ can be seen, which correspond to the microbaroms from the Ocean. Local wind noises (caused mainly by katabatic wind) are identified in several time windows during the four day.

on infrasound. The peak is considered to be generated near the coasts, where coastal swell reflection can provide the requisite opposing wave components. These period ranges corresponding to the 'microbaroms' are dictated by the physics of gravity wave generation, and are constrained by the speed and extent of Earth's surface winds (Figure 6).

In global scheme on seismology, the 'microseism' amplitudes are generally highest during local winter, because nearby oceans are stormier in winter than in summer [Stutzmann et al. 2009]. In polar region however, particularly Antarctica, the opposite observation has recently been reported: microseism amplitude is attenuated during local winter for the microseisms
[Grob et al. 2011]. The observation could be explained by the presence of the sea-ice extent impeding both the direct ocean-to-continent coupling and the coastal reflection which are the important components in generating the microseisms. Accordingly, it is expected that a similar phenomena of seasonal change will appear in the 'microbaroms' at Jang Bogo Station when we continue to monitor the data over a few years.

\section{Efficiency of infrasound monitoring}

Most of the scientific community agree that the polar region, both Arctic and Antarctic, play a critical role in the Earth system. The Southern Ocean and the Antarctic ice sheet, as well as the overlying atmosphere and its response to climate change potentially have a great impact upon the polar nature and on mankind. Monitoring the dynamic response of the polar ice sheet between the ocean-atmosphere-solid earth systems (Figure 1), would be crucial in the long-term effort to observe climate change on a global scale. Future directions in monitoring targets will emerge from the multi-disciplinary projects such as the EGG conducted by this study, combining the data with other global/regional networks.

A few infrasound monitoring stations have been operating around the LHB, East Antarctica by Japanese Antarctic Research Expedition (JARE) since 2008 [Ishihara et al. 2015]. Two infrasound arrays with different diameter triangles have been deployed at both inside the Syowa Station (100 m spacing) and on the continental ice sheet (1000 m spacing) from 2012-2013 austral summer [Murayama et al. 2015]. Besides these arrays, isolated single stations have been deployed at three outcrops in LHB. These arrays in LHB clearly identified the predominant propagating directions in NWN and their frequency content variations of "microbaroms" from Southern Indian Ocean (Figure 7).

When adopting array analysis to the data of infrasound stations at Jang Bogo, we are able to provide robust information about the propagating directions and apparent velocity from infrasound sources. An exact location of the sources could probably help to figure out their candidates in local environment. As future study, moreover, theoretical modeling studies [Ostrashev et al. 2005, de Groot-Hedlin, 2005] will be required in order to determine the actual source location and source mechanism of infrasound signals. It is also useful to compare these signals with other data, such as broadband seismograms and hydro-acoustics that share sensitivity over part of the infrasound frequency ranges [Starovoit and Martysevich 2005]. 


\section{Atmosphere-Ocean-Solid Earth Interactions}

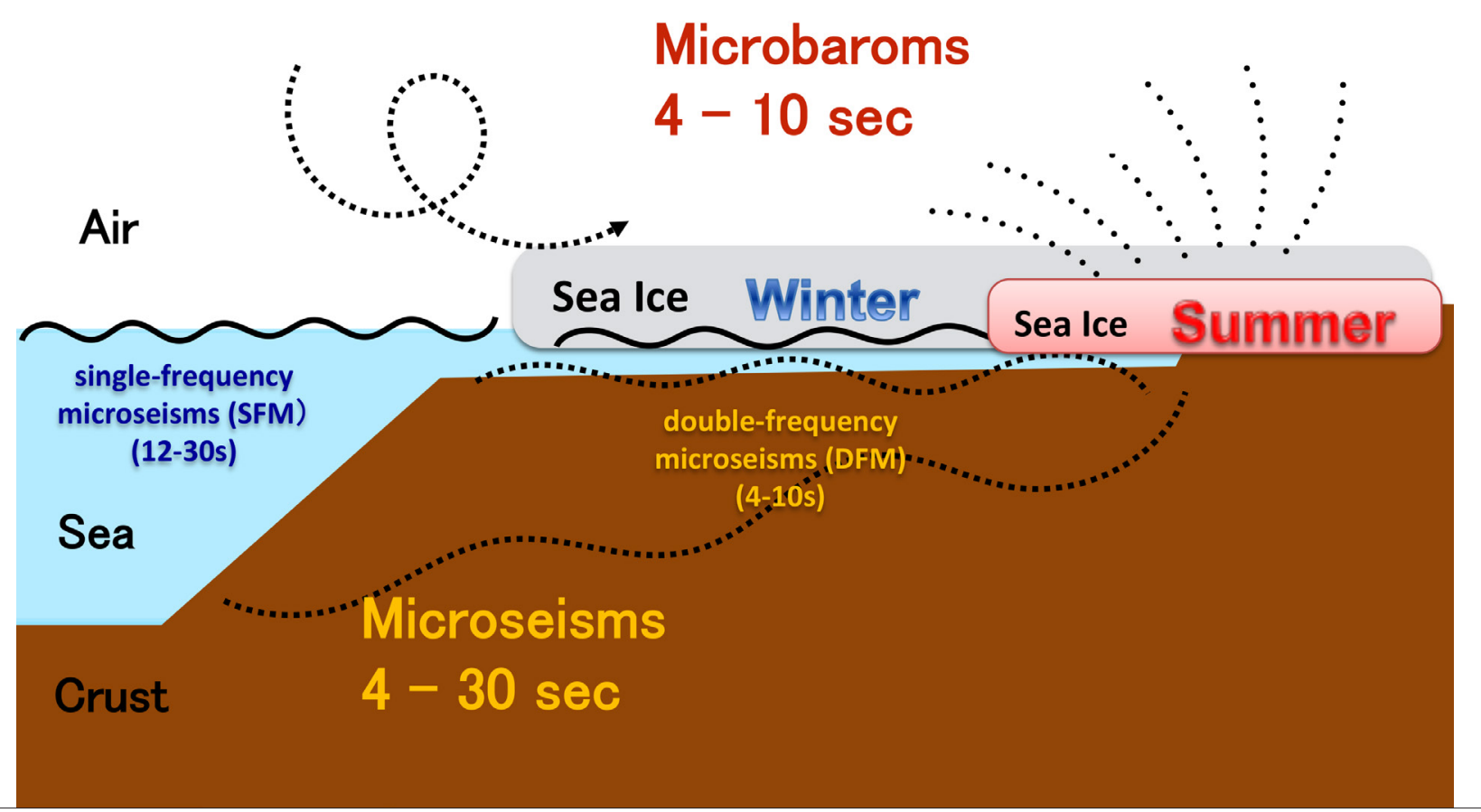

Figure 6. Schematic illustration of atmosphere-ocean-solid earth interactions to occur microbaroms and micoseisms in coastal environment in the Antarctic. The prominent infrasound powers (microbaroms) come from source regions in Southern Ocean and continental shelf along the margin of Antarctic continent. Seasonal variation in sea-ice spreading area and thickness affect strongly on the amplitude of microseisms (both for single-frequency microseisms (SFM) and double-frequency microseisms (DFM)).

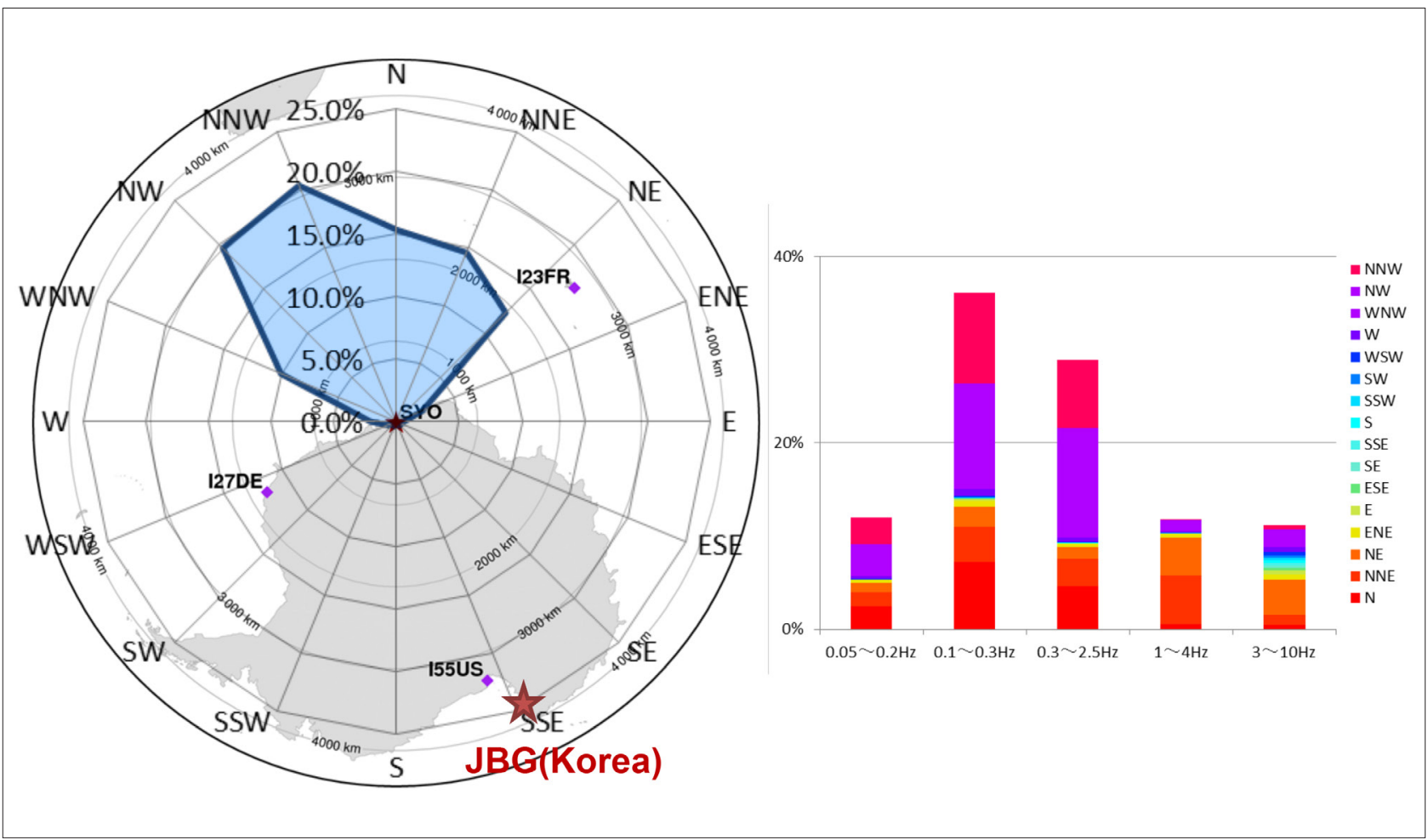

Figure 7. Occurrence rate (\%) of the detected predominant signals at Syowa Station (SYO) from 10 February to 31 March, 2013; left) A polar plot of all frequency bands at SYO. right) A histogram of five frequency bands, shown by different colors for each directions. Information of the other stations are as follows; I23 FR (Kerguelen), I27 DE (Georg von Neumayer), I55 US (Windless Bight), JBG (Jang Bogo). (modified after [Murayama et al. 2015]). 
Monitoring the infrasound waves in Antarctica, as the southern margins of the Southern Ocean, could be a new proxy for identifying regional environmental change among the global Earth system. There is still a lot to be learned about the physical mechanisms of interaction among atmosphere-ocean-cryosphere system in the Antarctic and surrounding oceans, in particular around Ross Sea and Northern Victoria Land.

\section{Conclusion}

Characteristic features of infrasound waves were observed in Terra Nova Bay, Northern Victoria Land, Antarctica by using the data from a broadband barometer deployed at Jang Bogo Station in mid-December 2015. The initial data recorded by the barometer include several kinds of signals originated surrounding the staiton, with contamination of natural local noises caused by katabatic winds. Continuous signals of oceanic origin ("microbaroms") were identically in austral summer data with predominant frequency content around $0.2 \mathrm{~Hz}$. Variabilities of their frequency and amplitude strength in Power Spectral Density could be affected by seasonal evolution of sea-ice surrounding the Terra Nova Bay. By utilizing the infrasound array combined by other three barometric sensors deploying insdie the Jang Bogo Staion, physical interaction involving surface environments around the coastal area and Southern Ocean will be clalified in future. Microbaroms measurement in the Antarctic is a useful tool for characterizing ocean wave climate, complementing other oceanographic, cryospheric and geophysical data. Continuous infrasound observations in the Terra Nova Bay should give rise to an answer for understanding the environmental changes involving global warming, cryosphere dynamics, volcanic eruption in the vicinity of Northern Victoria Land.

Acknowledgements. We would like to express our sincere appreciation to many collaborators for infrasound observations at Jang Bogo Station, as well as related members of the Korea Arctic and Antarctic Research Program. This work was supported by JSPS KAKENHI Grant Number 26241010 (P.I. by Dr. Masaki Kanao). The authors would like to express appreciaiton for an anonymous reviewer and an editorial office of Annals of Geophysics for publishing this paper.

\section{References}

Arai, N., Iwakuni, M., Watada, S., Imanishi, Y., Murayama, T., Nogami, M. (2011). Atmospheric boundary waves excited by the tsunami generation related to the 2011 great Tohoku-Oki earthquake, Geophys. Res. Lett., 38, L00G18, doi:10.1029/2011GL049146. Arrowsmith, S. J., Hedlin, M. A. H., Ceranna, L., Ed- wards, W. (2005). An Analysis of Infrasound Signals from the June 3rd, 2004 Fireball Over Washington State, InfraMatics, 10, 14-21.

Behrendt, J. C., and A. Cooper (1991). Evidence of rapid Cenozoic uplift of the shoulder escarpment of the Cenozoic West Antarctic rift system and a speculation on possible climate forcing, Geology, 19, 315-319.

de Groot-Hedlin, C. (2005). Modeling Infrasound Waveforms in a Windy Environment, InfraMatics, 11, 1-7.

Garces, M., McCormack, D., Servranckx, R., Bass, H., Hedlin, M., Yepes, H. (2007). Acoustic Surveillance for Hazardous Eruptions (ASHE): Preliminary results from a pilot infrasound experiment, In: 4th Inter. Workshop on Volcanic Ash, World Meteorol. Organ., Rotorua, N. Z.

Garces, M., Fee, D., Steffke, A., McCormack, D., Bass, H., Hetzer, C., Hedlin. M., Matoza, R. (2008). Capturing the Acoustic Fingerprint of Stratospheric Ash Injection, Eos Trans. AGU, 89(40), 377-378.

Grob, M., Maggi, A., Stutzmann, E. (2011). Observations of the seasonality of the Antarctic microseismic signal, and its association to sea ice variability, Geophys. Res. Lett., 38, L11302, doi:10.1029/2011GL047525.

Hedlin. M., Garces, M., Bass, H., Hayward, C., Herrin, G., Olson, J. V., Wilson, C. (2002). Listening to the secret sounds of Earth's atmosphere, Eos Trans. AGU, 83(48), 557, 564-565.

Ishihara, Y., M. Kanao, M.-Y. Yamamoto, S. Toda, T. Matshushima and T. Murayama (2015). Infrasound Observations at Syowa Station, East Antarctica - An Implication for Detecting the Surface Environmental Variations in Polar Region -, Geoscience Frontiers, 6, 285-296, doi:10.1016/j.gsf.2013.12.012.

Iyemori, T., Nose, M., Han, D. S., Gao, Y., Hashizume, M., Choosakul, N., Shinagawa, H., Tanaka, Y., Utsugi, M., Saito, A., McCreadie, H., Odagi, Y., Yang, F. (2005). Geomagnetic pulsations caused by the Sumatra earthquake on December 26, 2004, Geophys. Res. Lett. 32, L20807, doi:10.1029/2005GL024083.

Kanao, M., Maggi, A., Ishihara, Y., Yamamoto, M.-Y., Nawa, K., Yamada, A., Wilson, T., Himeno, T., Toyokuni, G., Tsuboi, S., Tono, Y., Anderson, K. (2012). Interaction of Seismic Waves between Atmosphere - Ocean - Cryosphere and Geosphere in Polar Region, In: Kanao, M., Takenaka, H., Murai, Y., Matsushima, J., Toyokuni, G. (Eds.), Seismic Waves Research and Analysis -, ISBN 978-953-307-944-8, InTech. Publisher, Rijeka, Croatia, 1-20. 
Le Pichon, A., Blanc, E., Drob, D. (2005). Probing high-altitude winds using infrasound, J. Geophys. Res., 110, D20104, doi:10.1029/2005JD006020.

Matoza, R. S., Hedlin, M. A. H., Garces, M. A. (2007). An infrasound array study of Mount St. Helens, J. Volcanol. Geotherm. Res., 160, 249-262.

Murayama, T., M. Kanao, M.-Y. Yamamoto, Y. Ishihara, T. Matshushima and Y. Kakinami (2015). Infrasound Array Observations in the Lützow-Holm Bay region, East Antarctica, Polar Science, 9, 35-50, doi:10.1016/j.polar.2014.07.005

Ostrashev, V. E., Wilson, D. K., Liu, L., Aldridge, D. F., Symons, N. P., Marlin, D. (2005). Equations for finite-difference, time-domain simulation of sound propagation in moving inhomogeneous media and numerical implementation, J. Acoust. Soc. Am., 117, 503-517.

Park, Y., H. J. Yoo, W. S. Lee, J. Lee, Y. Kim, S. H. Lee, D. Shin and H. Park (2014). Deployment and performance of a broadband seismic network near the new Korean Jang Bogo research station, Terra Nova Bay, East Antarctica, Seism. Res. Lett.,85, 1341-1347, doi: 10.1785/0220140107.

Rocchi, S., P. Armienti, M. D’Orazio, S. Tonarini, J. R. Wijbrans, and G. Di Vincenzo (2002). Cenozoic magmatism in the western Ross Embayment: Role of mantle plume versus plate dynamics in the development of the West Antarctic Rift System, Journal of Geophysical Research (Solid Earth), 107, 2195.

Starovoit, Y. O., Martysevich, P. N. (2005). Different Observed Mechanisms of Correlation Between Seismic and Pressure Signals, Inframatics, 9, 11-16.

Stutzmann, E., Schimmel, M., Patau, G., Maggi, A. (2009). Global climate imprint on seismic noise, Geochem. Geophys.Geosyst., 10, Q11004, doi:10.1029/2009GC002619.

Wilson, C. R. (1996). Auroral Infrasound Waves, J. Gephys. Res., 74, 1812-1836.

Wilson, C. R. (2005). Infrasound from Auroral Electrojet Motions at I53US, InfraMatics, 10, 1-13.

Wilson, C. R., Olson, J. V. (2005). Frequency Domain Coherence Between High Trace-Velocity Infrasonic Signals at I53US and Video Data from Pulsating Aurora, InfraMatics, 9, 27-30.

${ }^{*}$ Corresponding author: Masaki Kanao,

National Institute of Polar Research, Research Organization of Information and Systems, Tokyo, Japan; email: kanao@nipr.ac.jp.

2017 by Istituto Nazionale di Geofisica e Vulcanologia.

All rights reserved 